\title{
Contribution of Major Hydrophilic and Lipophilic Antioxidants from Papaya Fruit to Total Antioxidant Capacity
}

\author{
Laura E. Gayosso-García Sancho ${ }^{1}$, Elhadi M. Yahia ${ }^{2}$, Gustavo A. González-Aguilar ${ }^{3 *}$ \\ ${ }^{1}$ Jefatura de Nutrición Humana, Universidad Estatal de Sonora, Hermosillo, México; ${ }^{2}$ Facultad de Ciencias Naturales, Universidad \\ Autónoma de Querétaro, Querétaro, México; ${ }^{3}$ Coordinación de Tecnología de Alimentos de Origen Vegetal, Centro de Investigación \\ en Alimentación y Desarrollo, Hermosillo, México. \\ Email: "gustavo@ciad.mx
}

Received April $7^{\text {th }}, 2013$; revised May $7^{\text {th }}, 2013$; accepted May $15^{\text {th }}, 2013$

Copyright (C) 2013 Laura E. Gayosso-García Sancho et al. This is an open access article distributed under the Creative Commons Attribution License, which permits unrestricted use, distribution, and reproduction in any medium, provided the original work is properly cited.

\begin{abstract}
Several studies have shown that phenolic and carotenoid compounds protect against oxidative stress, reducing the risk of cardiovascular diseases and some types of cancers. The objective of this research was to determine the individual contribution of the main phenolic compounds from the papaya fruit skin and the individual contribution of main carotenoids from the pulp for total antioxidant capacity at four ripening stages; and the individual and combined radical scavenging ability used the essays DPPH (radical 2, 2-diphenyl-1-picryhydrazyl) and ABTS (radical 2, 20-azino-bis (3-ethylbenzothiazoline)-6 sulphonic acid). Phenolic acids standards for this study were ferulic (FA), caffeic (CA) and $\mathrm{p}$-coumaric $(\mathrm{pCA})$ acids and carotenoids studied were Lycopene, $\beta$-carotene and $\beta$-cryptoxanthin. The phenol that showed the best DPPH• and ABTS•+ radical scavenging ability was CA, with $89.47 \%$ and $92.98 \%$, respectively. Lycopene contributed the greatest to the TAC (11.9-43.2). Lycopene also showed the best DPPH• and ABTS•+ radical scavenging ability with $62.12 \%$ and $94.26 \%$, respectively. Antiradical ability of phenolics and carotenoids depended on the structure of the compound and its concentration.
\end{abstract}

Keywords: Carica Papaya; Carotenoids; Phenolics; Radical Scavenging Activity; TEAC; DPPH

\section{Introduction}

There is plenty of epidemiological evidence demonstrating the association between a diet rich in fresh fruits and vegetables and the reduction of the risk of certain types of cancer and cardiovascular diseases [1]. Free radicals and other reactive oxygen species (ROS) are constantly generated in vivo, playing a very important role in aging and in patogenesis of a number of degenerative diseases due to their ability to alter several biomolecules (lipids, carbohydrates, proteins, nucleic acids), changing their structure and function and ROS can be produced endogenously, namely by normal respiration, or result from exogenous sources [2]. Fruits and vegetables have valuable antioxidant compounds; the main protective action of these compounds is attributed to enzymes such as superoxide dismutase, catalasa and glutathione peroxidase, as well as to non-enzymatic antioxidants such as ascorbic

"Corresponding author. acid, $\alpha$-tocopherol, $\beta$-carotene, phenols, carotenoids among others [3].

Phenolic compounds in fruits and vegetables play an important role in the defense mechanism against oxidative stress caused by ROS and free radicals. Additionally, phenolic compounds show multiple biological activities such as antiproliferative, antiinflammatory, antimutagenic and antibacterial [4]. Their antiradical activity is based on the structural relation between the different parts of their chemical identity [5].

Carotenoids are liposoluble antioxidants. They quench singlet oxygen by a physical mechanism, in which the excess energy of singlet oxygen is transferred to another carotenoid's electron-rich structure [6].

Total antioxidant capacity of fruits and vegetables could be attributed to different mechanisms and the combination of these could create synergetic [7] antagonistic or additive effects [8]. Several methods have been used to 
evaluate the antioxidant capacity of natural compounds in several foods; the two most commonly used methods are DPPH (2, 2-diphenyl-1-picrylhydrazyl) and ABTS (2, 20-azinobis (3-ethyl-benzothiazoline-6-sulfonic acid)) [9]. The mechanisms of both assays are similar, although DPPH has a limitation regarding the interference of color and the solubility of the sample. The reaction is dependent of the ability of the sample to scavenge free radicals, which is registered quickly by the change of color from purple to yellow due to the capacity of donation of hydrogen [10]. On the other hand, ABTS radical has the advantage of being more versatile for polar samples and minimal interference on the spectrum when used at a maximum absorption of $760 \mathrm{~nm}$ [11]. The objective of this study was to evaluate the individual and combined contribution of the main phenolic and carotenoid compounds contained in papaya fruit var "Maradol" at different ripeness stages, and their total antioxidant capacity.

\section{Materials and Methods}

\subsection{Chemicals and Solvents}

n-Hexane, dichloromethane, ethanol, methanol, $\mathrm{K}_{2} \mathrm{~S}_{2} \mathrm{O}_{8}$, $\mathrm{Na}_{2} \mathrm{~S}_{2} \mathrm{O}_{3}$ were purchased from J. T. Baker (Baker Mallinckrodt, Mexico). Caffeic acid, ferulic acid, p-coumaric acid, lycopene (purity $\geq 90 \%$ ), $\beta$-carotene (purity $=95 \%$ ) from carrots, 2,2-Diphenyl-1-picrylhydrazyl (DPPH·), 2,2_-azinobis(3-ethylbenzo-thiazoline-6-sulfonate) ABTS $^{+}$, Trolox (6-hydroxy-2,5,7,8-tetramethylchromane2-carboxylic acid) were from Sigma Chemical Co. (St. Louis MO, USA).

\subsection{Plant Material}

Papaya fruit (C. papaya L, cv. Maradol) were obtained from a local market in Hermosillo, Sonora, Mexico. Fruit were selected for uniform size, color, level of external ripeness, and divided into four ripeness stages: RS1 represents papaya with yellow area on $0 \%-25 \%$ of the skin; RS2 with $>25 \%$ - 50\% color; RS3 with $>50 \%$ $75 \%$, and RS4 with $>75 \%-100 \%$. The Physiological and Biochemical Parameters were made according GayossoGarcía Sancho et al. [12]. After selection, fruit were divided into lots of 12 fruit each, and flesh and skin were randomly sampled and then were freeze-dried and stored at $-70^{\circ} \mathrm{C}$ until analysis.

\subsection{Sample Preparation}

Stock standard solutions $\left(1 \mathrm{mmol} \cdot \mathrm{L}^{-1}\right)$ in methanol and acetone were prepared for each RS and appropriate dilutions were done for each type of measurement with the specific solvent of each method.

\subsection{Extraction of Hydrophilic Fractions}

Preparation of phenolic acids was done according to a modified method described by Gayosso-García Sancho et al. [12]. Papaya skin dry samples $(0.5 \mathrm{~g})$ were homogenized in $20 \mathrm{~mL}$ of $80 \%$ methanol, using an Ultra Tur$\operatorname{rax}^{\circledR} \mathrm{T} 25$ basic homogenizer (IKA Works, Willmington, $\mathrm{NC}$ ), sonicated for $30 \mathrm{~min}$ at $30^{\circ} \mathrm{C}$ in a 2510 model ultrasonic bath (Branson, Whetersfield, CT), centrifuged at $12,000 \mathrm{~g}$ for $15 \mathrm{~min}$ at $5^{\circ} \mathrm{C}$ in a Hermle centrifuge model Z323 K (Labortechnik Technologies, Germany), and then filtered through number 1 Whatman paper. For the alkaline hydrolysis $10 \mathrm{~mL}$ of $4 \mathrm{M} \mathrm{NaOH}$ were added to phenolic extracts and left for $4 \mathrm{~h}$ in the dark at room temperature. Alkaline hydrolysis of extracts improved separation of compounds. After incubation, extracts were acidified to $\mathrm{pH} 2.0$ with $4 \mathrm{M} \mathrm{HCl}$, then, the acidified solutions were extracted twice with $20 \mathrm{~mL}$ ethyl acetate. Extracts were evaporated in a Rotovapor ${ }^{\circledR}$ (Büchi Labortechnik AG, Flawil, Switzerland) at $35^{\circ} \mathrm{C}$ in a Buchi low-pressure evaporator. Skin samples were resuspended in 10 $\mathrm{mL}$ of $80 \%$ methanol and stored at $-78^{\circ} \mathrm{C}$ to be used in the DPPH and ABTS assays.

\subsection{Extraction of Lipophilic Fractions}

Carotenoids were determined according to Gayosso- García Sancho et al. [12] and Ornelas-Paz et al. [13]. Freezedried papaya tissue $(0.5 \mathrm{~g})$ was homogenized in $10 \mathrm{~mL}$ of hexane: dichloromethane $(1: 1, \mathrm{v} / \mathrm{v})$, using an Ultra Tur$\operatorname{rax}^{\circledR} \mathrm{T} 25$ basic homogenizer (IKA Works, Willmington, $\mathrm{NC}$ ) and centrifuged at $9000 \mathrm{~g}$ for $10 \mathrm{~min}$ at $5^{\circ} \mathrm{C}$. Organic phase was separated, and procedure was repeated three times. For alkaline hydrolysis $10 \mathrm{~mL}$ of methanolic $\mathrm{KOH} 40 \%(1: 1, \mathrm{v} / \mathrm{v})$ was added to extracts for $1 \mathrm{~h}$ at $50^{\circ} \mathrm{C}$ in a stirring bath set at $100 \mathrm{rpm}$. After saponification, $10 \mathrm{~mL}$ of $10 \%$ sodium sulfate was added for phase separation and the extracts were left for $1 \mathrm{~h}$ in the dark at room temperature. TC quantification was measured on top-phase aliquots in a Beckman DU-65 spectrophotometer at 450 and $470 \mathrm{~nm}$. Extracts were evaporated in a Rotovapor $^{\mathbb{B}}$ (Büchi Labortechnik AG, Flawil, Switzerland) at $30^{\circ} \mathrm{C}$ in a Buchi low-pressure evaporator. Flesh samples were resuspended in $2 \mathrm{~mL}$ acetone and stored at $-78^{\circ} \mathrm{C}$ to be used in the DPPH and TEAC assays.

\subsection{Antioxidant Capacity Assay Using DPPH Radical}

DPPH was determined according to the method reported by Brand-Williams et al. [14] with minor modifications for hydrophilic and lipophilic fractions, as well as for individual pure phenolics and carotenoids. The DPPH assay is based on the measurement of antioxidants' ability to lower radical DPPH• (2, 2-diphenyl-1-picrylhydrazyl). 
The test is quick and simple, and only a UV-vis spectrophototometer is needed to perform it, being the reason for its widespread use for the analysis of antioxidant capacity [15]. The stock solution was prepared by mixing $2.5 \mathrm{mg}$ of DPPH • radical with $100 \mathrm{~mL}$ of pure methanol. The solution was adjusted at an absorbance of $0.7 \pm 0.02$ at $515 \mathrm{~nm}$. Trolox (6-hydroxy-2, 5, 7, 8-tetramethylchromane-2-carboxylic) was used as a standard and $80 \%$ methanol was used as a blank, $3.9 \mathrm{~mL}$ of $\mathrm{DPPH} \bullet$ radical were placed in a test tube and $100 \mu \mathrm{L}$ of the extract were added. The mixture was shaken in a vortex and kept 30 min in the dark. The absorbance was read at $515 \mathrm{~nm}$ in an UV-VIS VARIAN CARY 50 BIO spectrophotometer. Antioxidant capacity of pure phenolics, carotenoids and each RS was expressed as Radical Scavenging Ability (\%). Analyses were performed with a minimum of 6 replications.

\subsection{Antioxidant Capacity Assay Using ABTS Radical}

ABTS radical-scavenging activity for hydrophilic and lipophilic fractions and individual pure phenolics and carotenoids was determined according to Miller et al. [16] and Re et al. [17]. ABTS $\bullet+$ cation was generated through the interaction of $19.2 \mathrm{mg}$ of ABTS (2'2-azino-bis(3ethylbenzotriazoline-6-sulfonic acid), dissolved in $5 \mathrm{~mL}$ of HPLC-grade water and $88 \mu \mathrm{L}$ of potassium persulfate $\left(0.0378 \mathrm{~g} \cdot \mathrm{mL}^{-1}\right)$. The solution was held at room temperature in the dark for $16 \mathrm{~h}$, then $1 \mathrm{~mL}$ of ABTS activated radical was taken and $88 \mathrm{~mL}$ of ethanol was added. The radical was adjusted at an absorbance of $0.7 \pm 0.02$ at $734 \mathrm{~nm}$. The reaction was initiated adding $2970 \mu \mathrm{L}$ of ABTS $\bullet+$ and $30 \mu \mathrm{L}$ of the extract. The absorbance at 734 $\mathrm{nm}$ was measured at 1 and 6 min and antioxidant capacity of pure phenolics, carotenoids and each RS was expressed as Radical Scavenging Ability (\%). Analyses were performed with a minimum of 6 replications.

\subsection{Statistical Analysis}

The statistical significance of differences was analyzed through an analysis of variance (ANOVA) and the multiple comparisons of means through the Duncan's test. Statistical differences were considered to be significant ( $\mathrm{p} \leq$ 0.05 ) using the statistical software SAS version 8.0 (SAS Inst. Inc.Cary, NC, USA).

\section{Results and Discussion}

\subsection{Percentage of Individual Contribution of Phenolic Compounds from Papaya Fruit Skin to TAC}

In previous studies by Gayosso-García Sancho et al. [18], once the total antioxidant capacity (TAC) was deter- mined, we focused on the identification and quantification of the main phenolic compounds that are present at the highest concentrations in papaya skin [18], those being caffeic, ferulic and $p$-coumaric acids; only traces were found in the pulp. These results coincide with previous reports from Rivera-Pastrana et al. [19] in papaya fruit. Research done in other fruits have indicated that hydroxicinnamic acids are generally more abundant than hydroxibenzoic acids, and that skins have greater concentration of phenolic compounds than pulp [20,21], that their concentration decreased during ripening stages [22], and influenced by geography, variety and ripeness stages [23].

Later, an evaluation was performed of the individual contribution to TAC of phenolic compounds of papaya fruit skin in the hydrophilic extract. Figure 1 shows the percentage of individual contribution of phenolic compounds. This calculation was done based on the TAC, which represents $100 \%$, and using standards of these phenolic acids according to the content found on the fruit at each of the ripening stages. It is possible to note that as RS increased, the contribution of caffeic and ferulic acids decreased from $14.98 \%$ to $8.09 \%$ and from $6.92 \%$ to $6.22 \%$, respectively; while $p$-coumaric acid increased from 0.86 to 0.94 . The rest of the $100 \%$ could be vitamin $\mathrm{C}$, sugars and other phenols. Even when the concentration of caffeic acid is lower than other acids, it is evident that the percentage of contribution to TAC is greater, because its activity depends mainly on its structure (dissociation energy, resonance, and steric hindrance derived from the substitution of hydrogen in the aromatic ring) and on its concentration in the food matrix [9]. A study performed by Jaikang and Chaiyasut [24] concluded that the antioxidant activity of caffeic acid is due to its possi-

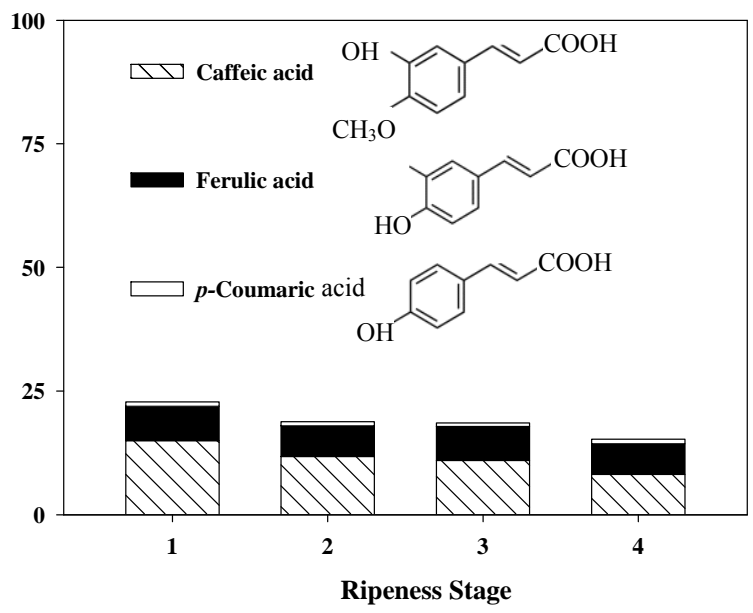

Figure 1. Percentage of the contribution of total antioxidant capacity (TAC) of the main phenolic acids in the skin of papaya fruit var. "Maradol" at different ripeness stages (RS). 
ble relationship with the two hydroxyl groups present in the benzenic ring. In the case of ferulic acid the presence of the metoxi group decreases the antioxidant capacity [25] concluding that ferulic acid is less effective than caffeic acid.

\subsection{Percentage of Carotenoids' Individual Contribution to TAC in Papaya Pulp}

Just as in phenolic compounds, once TAC was determined, we focused on the identification and quantification of the main carotenoids that are present in highest concentrations in the lipophilic portion of the extract of papaya fruit pulp [12]. The highest concentration of carotenoids in papaya pulp: lycopene, $\beta$-carotene and $\beta$-cryptoxanthin; their concentration was inclined to increase with the process of ripening of the fruit. These results coincide with previous reports from Rivera-Pastrana et al. [19] and Wall [26] in papaya fruit. Figure 2 shows the percentage of carotenoids' individual contribution. This calculation was done based on the TAC, and using the standards for these carotenoids, according to the contents found in the fruit at each RS.

It was observed that as RS advanced, generally the contribution of carotenoids increased, providing a total contribution of $32.23 \%, 41.29 \%, 51.52 \%$ and $82.86 \%$ at RS1, 2, 3 and 4, respectively. The rest could be due to other carotenoid compounds and lipoproteins. The distinctive structural characteristic of carotenoids is formed by an extensive system of double conjugated links, which consist in the alternation of simple and double carboncarbon links that get stabilized by a resonance called polyenic chain. This part of the molecule, known as chromophore, is responsible for carotenoids' capacity for light absorption in the visible region, and consequently their

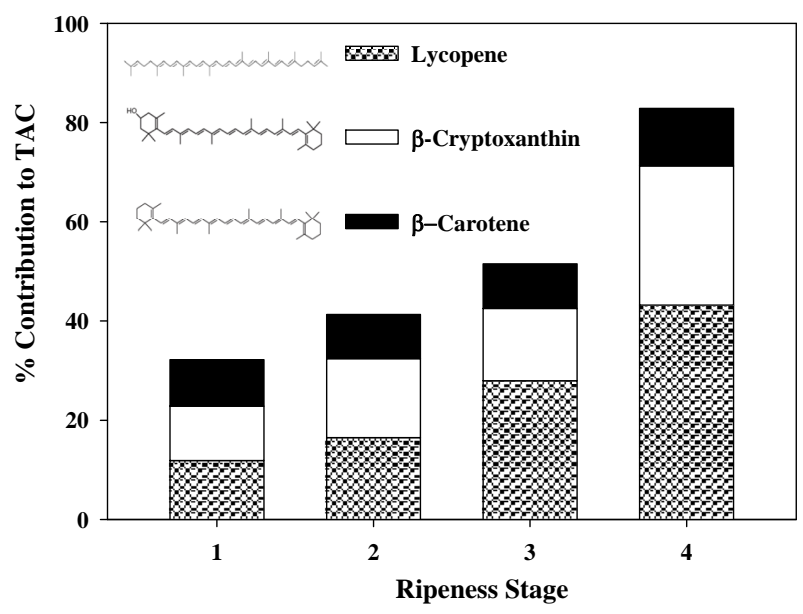

Figure 2. Percentage of the contribution to TAC of the main carotenoids in papaya fruit var. "Maradol" at different RS. great capacity for coloration and as antioxidants, giving them the ability to eliminate singlet oxygen and scavenge other reactive species of oxygen [6].

A study performed by Jimenez-Escrig et al. [27] showed that antioxidant capacity increased by the length of the system of the conjugated double links, and that it could be reduced with the addition of terminal rings (xanthophylls). On the other hand, studies done by Mortensen et al. [28] showed that the presence of an hydroxyl group in the terminal ring, such as in the case of $\beta$-cryptoxanthin, increased the antioxidant capacity, but at the same time this one is lower than the one provided by lycopene.

\subsection{Evaluation of the Effect of Individual and Combined Phenolic Compounds on the Antioxidant Capacity (\% Radical Scavenging Ability)}

Once the percentage of contribution of phenolic compounds to TAC was determined, the next step was to determine their individual and combined antioxidant capacity, using $\mathrm{DPPH} \bullet$ and ABTS $\bullet+$ radicals.

For the evaluation of the percentage of individual radical scavenging ability, phenolic acid standards were used in the quantified concentrations at different RS. Figure 2 shows DPPH - scavenging ability of these compounds. Significant differences were observed in the scavenging ability of phenolic acids. This ability decreased in the order of CA $(89.47 \%)>$ FA $(62.27 \%)>$ pCA $(43.43 \%)$. Results clearly show the importance of the effects of phenolic structure, because antioxidant activity of hydroxycinnamic acids depends on the number of hydroxyl groups on the molecule, in addition of the effect given by the steric hindrance of their carboxyl group [29]. In a study performed to determine the antioxidant capacity of caffeic acid, it was observed that the capacity depended on the two hydroxyl groups that exist in the acid, and that every caffeic molecule could trap two peroxyl radicals [30].

Additionally, the effect of the combination of two or more phenols in the antioxidant capacity was evaluated, as shown on Figure 3. The combination of CA and FA increased the antioxidant capacity by $93 \%$, while the combination of $\mathrm{CA}$ and $\mathrm{pCA}$ reduced the capacity by $78 \%$. The combination of FA and pCA resulted in the reduction of antioxidant capacity (57.71\%), in comparison with the individual effect of FA. When combining the three phenolic acids, radical scavenging ability was of $84.8 \%$ being a lower percentage compared to the obtained individually from the CA. A synergetic effect is produced when two or more antioxidants are present in a system, resulting in a total superior effect, which could be estimated by simple addition of their individual actions [31]. In general, results show that the combination 
of CA and FA creates a significant synergy in the antioxidant capacity with respect to the individual use of these compounds, while the effect is lower with the combination of the three phenolic acids.

Because the application of at least two essays is recommended to obtain more accurate information about the antioxidant capacity of a compound, an essay of TEAC was performed, which is based on the ability of antioxidants in the inhibition of radical cation ABTS •+ absorbance, through the donation of an electron or an $\mathrm{H} \cdot$ reacting in aqueous and organic solvents [32]. Figure 3 shows the results obtained for phenolic acids, which were similar and slightly higher than the results obtained with DPPH essay. Several epidemiological studies suggest an inverse relation between the consumption of foods rich in phenolic acids and the occurrence of a variety of diseases. Kang, et al. [33] found that CA inhibited the activity of Fyn kinase, which belongs to the family of non-receptive proteins of tyrosine kinase, suppressing skin carcinogenesis, which suggests a chemo-preventive effect of this type of cancer. In a study performed by Chung et al. [34], liver metastasis was reduced significantly, confirming the anti-tumoral and anti-metastatic effects of CA and caffeic acid phenethylester (CAPE). With respect to the antioxidant and anti-inflammatory capacity of ferulic acid, it has been observed that this acid has positive effects against Alzheimer when mice were treated with FA, reducing the activity of the coline acetyltransferase [35]. In general, synergetic or antagonic effects of the compounds will depend on their structure, reactive mechanism and the nature of the radical.

\subsection{Evaluation of the Individual and Combined Effect of Carotenoids on the Antioxidant Capacity (\% Radical Scavenging Ability)}

Following the determination of carotenoids' percentage of contribution to TAC, we determined their individual and combined antioxidant capacity, using $\mathrm{DPPH} \bullet$ and ABTS $\bullet+$ radicals. During the individual evaluation of the percentage of radical scavenging ability, carotenoid standards were used for the quantification at different RS. Figure 3 shows the DPPH scavenging ability of these compounds; where significant differences are observed in the antioxidant activity of lycopene $(62.12 \%)$ and $\beta$ carotene (12.06\%). Carotenoids possess strong differences in their redox potentials, due to their molecular structure.

A study performed to determine the antioxidant capacity of several carotenoids concluded that this capacity depends on the structure of each specific carotenoid; increasing in the following order: lycopene $>\beta$-cryptoxanthin $>\alpha$-carotene $>\beta$-carotene $>$ zeaxanthin $>$ lutein [27]. Several in vitro studies have indicated that lycopene is a powerful antioxidant, a quencher of singlet oxygen, and has the ability to scavenge free radicals [36]. In the meantime, $\beta$-carotene eliminates free radicals, neutralizes singlet oxygen and protects DNA from its mutagenic activity [37]. One mole of $\beta$-carotene can quench 250 to 1000 molecules of singlet oxygen [38] and may donate electrons instead of hydrogen atom to free radicals, and posses $\beta$-carotene radical action [28].

During this study, we obtained values for the percentage of radical scavenging ability, due to carotenoids' double link structure, with spectrums that can overlap on radical $\mathrm{DPPH} \cdot$ at $515 \mathrm{~nm}$, resulting in the recording of lower values [39]. In contrast, the use of the TEAC assay showed superior values in the antioxidant capacity. $\beta$ carotene had a $30 \%$ radical scavenging ability, while lycopene was three times higher (94.26\%) (Figure 3). Lycopene's quenching ability is related to the aperture of the b-ionone ring in its chain [40]. Carotenoids' antioxidant capacity depends on the number of conjugated double links and on the presence of oxygenated functions in its molecule [41].

On the other hand, Figure 3 shows the results obtained when the combination of lycopene and $\beta$-carotene's scavenging ability was measured using radical $\mathrm{DPPH} \bullet$ and ABTS $\bullet+$, where this combination did not increase antioxidant capacity (61.76\%), compared to the individual results from lycopene using the DPPH assay, and at the same time there were no significant differences in the individual and combined evaluation using the TEAC assay $(93.46 \%)$. While comparing the molecular structures of lycopene and $\beta$-carotene, it has been confirmed that carotene's ability for scavenging radical ABTS increases with the extension of cromophore [16]. Other studies have indicated that the mix of carotenoids has been more effective against liposome oxidation, that the use of individual carotenoids and that the combination with lycopene and lutein promote a synergetic effect, increasing the antioxidant activity of the mix, in comparison with a low synergetic effect obtained when using individually $\alpha$-carotene, $\beta$-carotene, and other carotenoids [42].

Other studies have suggested that antioxidant activity is the result of the combination of each one of the components of the mix, and that a synergetic or antagonist effect can be generated, depending on the environment where the compounds are found [43]. In addition of antioxidant activity, carotenoid compounds have important biological activities, such as the stimulation of the intercellular communication, the control of cellular growth, the intercellular differentiation in growth control, cell differentiation (mutagenesis inhibition), and the modulation of immune response [6]. Results suggest that scavenging ability of the combination of carotenoids was higher than the one presented by $\beta$-carotene alone, which 


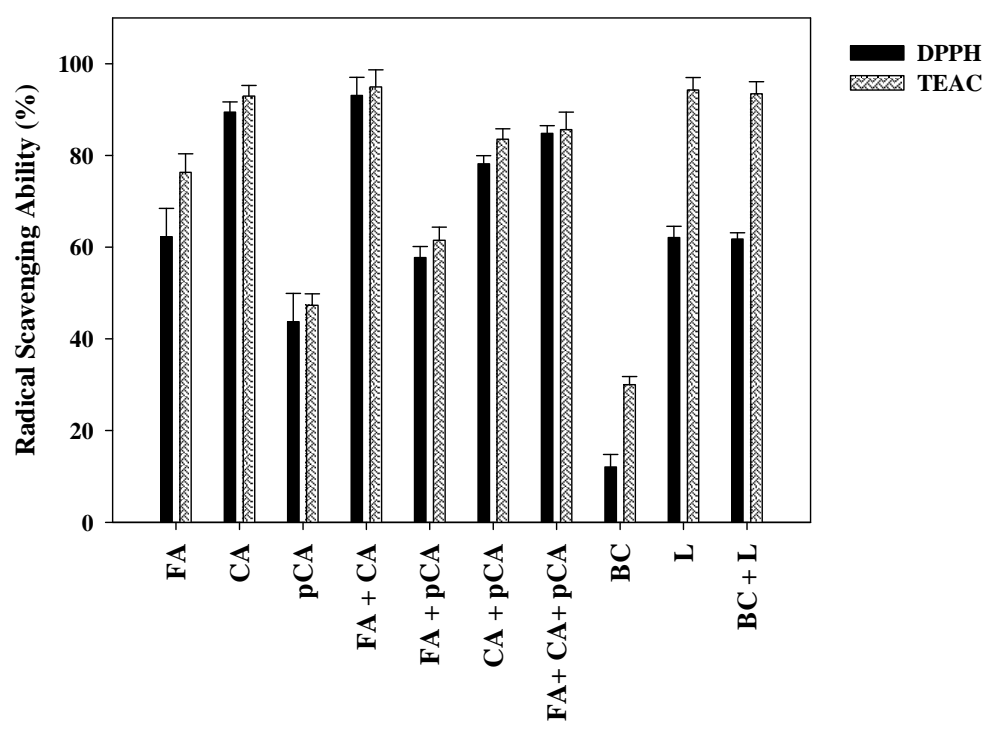

Figure 3. Radical Scavenging Ability (\%) of single phenolics, carotenoids and in combination measured by DPPH and TEAC assays (FA: ferulic acid; CA: caffeic acid; pCA: p-Coumaric acid; BC: $\beta$-Carotene; L: Lycopene.

is in favor of the increase of antioxidant capacity of these types of compounds.

In summary, synergistic interactions could occur between the major antioxidants present in papaya. Palafox-Carlo [44] reported the interactions that occur between major phenolics present in "Ataulfo" mango. These authors observed that gallic and protocatechuic acid exhibited the highest antioxidant capacity, probably due to their particular chemical conformation and hydroxyl groups content. According to our observations, the phenolic acids and carotenoids present in papaya can interact, and their interactions can affect the total antioxidant capacity of a solution. However, more work is needed in order to explain the possible synergism of the antioxidants and how they are contributing to the total antioxidant activity. Based on these results, the importance of choosing the different fruit that in combination of their antioxidants may be advantage when designing functional foods. As we mentioned before [44], more studies with combinations are required in a more mechanistic way, including infrared spectrometry and magnetic nuclear resonance, in order to better understand the mechanisms that are taking place inside an antioxidant system. Also, further studies are needed to evaluate the bioabsortion, biodisponibility and interactions between these compounds present in papaya pulp and other tropical fruits, after consumption.

\section{Conclusion}

Our results showed that the contribution of phenolic acids to the TAC depended mostly on their structure, that the combination of ferulic acid and caffeic acid had the best radical scavenging ability, while the combination of caffeic, ferulic and p-coumaric acids did not show a synergetic effect that could contribute to increasing antioxidant capacity. In relation to the contribution of carotenoids to the TAC, lycopene was the compound that contributed the most, followed by $\beta$-criptoxanthin, showing again that the structure of the molecule played an important role in the results obtained. Radical scavenging ability results showed that the interaction of lycopene with $\beta$-carotene did not have an antagonic effect and this mix could be considered for the design of dietary supplements that could contribute to the improvement of human health.

\section{REFERENCES}

[1] M. E. Yahia, "The Contribution of Fruit and Vegetable Consumption to Human Health," In: L. A. de la Rosa, Ed., Fruit and Vegetable Phytochemicals, New York, 2010, pp. 3-51.

[2] M. Genestra, "Oxyl Radicals, Redox-Sensitive Signaling Cascades and Antioxidants," Cellular Signaling, Vol. 19, No. 1, 2007, pp. 1807-1819. doi:10.1016/j.cellsig.2007.04.009

[3] Ch. Teow, V. Truong, R. F. McFeeters, R. L. Thompson, K. V. Pecota and G. C. Yencho, "Antioxidant Activities, Phenolic and B-Carotene Contents of Sweet Potato Genotypes with Varying Flesh Colours," Food Chemistry, Vol. 103, No. 1, 2007, pp. 829-838. doi:10.1016/j.foodchem.2006.09.033

[4] S. J. Kim and G. H. Kim, "Quantification of Quercetin in Different Parts of Onion and Its DPPH Radical Scavenging and Antibacterial Activity," Food Science Biotechnology, Vol. 15, No. 1, 2006, pp. 39-43.

doi:10.3390/ijms12063757 
[5] C. Rice-Evans, N. J. Miller and G. Paganga, "StructureAntioxidant Activity Relationships of Flavonoids and Phenolic Acids," Free Radical Biology \& Medicine, Vol. 20, No. 1, 1996, pp. 933-956. doi:10.1016/0891-5849(95)02227-9

[6] M. E. Yahia and J. J. Ornelas-Paz, "Chemistry, Stability and Biological Actions of Carotenoids," In: L. A. de la Rosa, Ed., Fruit and Vegetable Phytochemicals, New York, 2010, pp. 177-222.

[7] Q. Y. Wei, B. Zhou, Y. J. Cai, L. Yang and Z. L. Liu, "Synergistic Effect of Green Tea Polyphenols with Trolox on Free Radical-Induced Oxidative DNA Damage," Food Chemistry, Vol. 96, No. 1, 2006, pp. 90-95. doi:10.1016/j.foodchem.2005.01.053

[8] P. Iacopini, M. Baldi, P. Storchi and L. Sebastiani, "Catechin, Epicatechin, Quercetin, Rutin and Resveratrol in Red Grape: Content, in Vitro Antioxidant Activity and Interactions," Journal of Food Composition and Analysis, Vol. 21, No. 1, 2008, pp. 589-598. doi:10.1016/j.jfca.2009.05.004

[9] H. J. Heo, Y. J. Kim, D. Chung and D. O. Kim, "Antioxidant Capacities of Individual and Combined Phenolics in a Model System," Food Chemistry, Vol. 104, No. 1, 2007, pp. 87-92. doi:10.1016/j.foodchem.2006.11.002

[10] C. M. Ajila, K. A. Naidu, S. G. Bhat and R. U. J. S. Prasada, "Bioactive Compounds and Antioxidant Potential of Mango Peel Extract," Food Chemistry, Vol. 105, No. 1, 2007, pp. 982-988. doi:10.1016/j.foodchem.2007.04.052

[11] R. Re, N. Pellegrini, A. Proteggente, A. Pannala, M. Yang and C. Rice-Evans, "Antioxidant Activity Applying an Improved ABTS Radical Cation Decolorisation Assay," Free Radical Biology \& Medicine, Vol. 26, No. 9-10, 1999, pp. 1231-1237.

[12] L. E. Gayosso-García Sancho, E. M. Yahia and G. A. González-Aguilar, "Identification and Quantification of Phenols, Carotenoids, and Vitamin C from Papaya (Carica Papaya L., cv. Maradol) Fruit Determined by HPLC-DADMS/MS-ESI," Food Research International, Vol. 44, No. 5, 2011, pp. 1284-1291. doi:10.1016/i.foodres.2010.12.001

[13] J. J. Ornelas-Paz, M. E. Yahia and A. Gardea, "Changes in External and Internal Color during Postharvest Ripening of "Manila" and "Ataulfo" Mango Fruit and Relationship with Carotenoid Content Determined by Liquid Chromatography-APcI+-Time-of-Flight Mass Spectrometry," Postharvest Biology and Technology, Vol. 50, No. 1, 2008, pp. 145-152. doi:10.1016/i.postharvbio.2008.05.001

[14] W. Brand-Williams, M. E. Cuvelier and C. Berset, "Use of a Free Radical Method to Evaluate Antioxidant Activity," Lebensmittel-Wissenschaft \& Technologie, Vol. 28, No. 1, 1995, pp. 25-30.

[15] P. Molyneux, "The Use of the Stable Radical Dipheylpicrylhydrazyl (DPPH) for Estimating Antioxidant Activity," Songklanakarin Journal of Science and Technology, Vol. 26, No. 1, 2004, pp. 211-219.

[16] N. J. Miller, J. Sampson, L. Canadeias, P. M. Bramley and C. A. Rice-Evans, "Antioxidant Activities Carotenes and Xanthophylls," Free Radical Research, Vol. 384, No. 3, 1996, pp. 240-242.

[17] R. P. Re, N. A. Proteggente, A. Pannala, M. Yang and C. Rice-Evans, "Antioxidant Activity Applying an Improved ABTS Radical Cation Decolonization Assay," Free Radical Biology \& Medicine, Vol. 26, No. 9-10, 1998, pp. 1231-1237. doi:10.1016/S0891-5849(98)00315-3

[18] L. E. Gayosso-García Sancho, E. M. Yahia, M. A. Martínez-Téllez and G. A. González-Aguilar, "Effect of Maturity Stage of Papaya Maradol on Physiological and Biochemical Parameters," American Journal of Agricultural and Biological Sciences, Vol. 5, No. 2, 2010, pp. 199-208. doi:10.3844/ajabssp.2010.194.203

[19] D. M. Rivera-Pastrana, E. M. Yahia and G. Gonzalez-Aguilar, "Phenolic and Carotenoid Profiles of Papaya Fruit (Carica papaya L.) and their Contents Under Low Temperature Storage," Journal of the Science of Food \& Agriculture, Vol. 90, No. 14, 2010, pp. 2358-2365. doi:10.1002/jsfa.4092

[20] N. Castillo-Muñoz, M. Fernández-González, S. GómezAlonso, E. García-Romero and I. Hermosín-Gutiérrez, "Red-Color Related Phenolic Composition of Garnacha Tintorera (Vitis vinifera L.) Grapes and Red Wines," Journal of Agricultural of Food Chemistry, Vol. 57, No. 17, 2009, pp. 7883-7891. doi:10.1021/jf9002736

[21] A. L. Gancel, P. Alter, C. Dhuique-Mayer, J. Rualesand and F. Vaillant, "Identifying Carotenoids and Phenolic Compounds in Naranjilla (Solanum quitoense Lam. var. Puyo hybrid), an Andean Fruit," Journal of Agricultural of Food Chemistry, Vol. 56, No. 24, 2008, pp. 11890-11899. doi:10.1021/jf801515p

[22] H. El Gharras, "Polyphenols: Food Sources, Properties and Applications-A Review," International Journal of Food Science \& Technology, Vol. 44, No. 12, 2009, pp. 25122518. doi:10.1111/j.1365-2621.2009.02077.x

[23] J. Sun, F. Liang, Y. Bin, P. Li and C. Duan, "Screening Non-Colored Phenolics in Red Wines Using Liquid Chromatography/Ultraviolet and Mass Spectrometry/Mass Spectrometry Libraries," Molecules, Vol. 12, No. 3, 2007, pp. 679-693. doi:10.3390/12030679

[24] C. Jaikang and C. Chaiyasut, "Caffeic Acid and Its Derivatives as Heme Oxygenase 1 Inducer in Hep G2 Cell Line," Journal of Medicinal Plants Research, Vol. 4, No. 10, 2010, pp. 940-946.

[25] P. Kylli, P. Nousiainen, P. Biely, J. Sipila, M. Tenkanen and M. Heinonen, "Antioxidant Potential of Hydroxycinnamic Acid Glycoside Esters," Journal of Agricultural of Food Chemistry, Vol. 56, No. 12, 2008, pp. 4797-4805. doi: $10.1021 / \mathrm{jf} 800317 \mathrm{v}$

[26] M. M. Wall, “Ascorbic Acid, Vitamin A, and Mineral Composition of Banana (Musa sp.) and Papaya (Carica papaya) Cultivars Grown in Hawaii," Journal of Food Composition \& Analysis, Vol. 19, No. 1, 2006, pp. 434-445. doi:10.1016/j.jfca.2006.01.002

[27] A. Jiménez-Escrig, I. Jiménez-Jiménez, C. Sánchez-Moreno and F. Saura-Calixto, "Evaluation of Free Radical Scavenging of Dietary Carotenoids by the Stable Radical 2,2-dip Henyl-1-picrylhydrazyl," Journal of the Science 
of Food \& Agriculture, Vol. 80, No. 11, 2000, pp. 16861690.

doi:10.1002/1097-0010(20000901)80:11<1686::AID-JSF A694>3.0.CO;2-Y

[28] A. Mortensen, L. H. Skibsted and T. G. Truscott, "The Interaction of Dietary Carotenoids with Radical Species," Archives of Biochemistry and Biophysics, Vol. 385, No. 1, 2001, pp. 13-19. doi:10.1006/abbi.2000.2172

[29] F. Shahidi and A. Chandrasekara, "Hydroxycinnamates and Their in Vitro and in Vivo Antioxidant Activities," Phytochemistry Reviews, Vol. 9, No. 1, 2010, pp. 147-170. doi:10.1007/s11101-009-9142-8

[30] J. H. Chen and C. Ho, "Antioxidant Activities of Caffeic Acid and Its Related Hydroxycinnamic Acid Compounds," Journal of Agricultural of Food Chemistry, Vol. 45, No. 7, 1997, pp. 2374-2378. doi:10.1021/jf970055t

[31] E. A. González and M. A. Nazareno, "Antiradical Action of Flavonoide Ascorbate Mixtures," Food Science \& Technology, Vol. 44, No. 2, 2011, pp. 558-564.

[32] S. Knasmüller, A. Nersesyan, M. Misik, C. Gerner, W. Mikulits, V. Ehrlich, C. Hoelz, A. Szakmary and K. H. Wagner, "Use of Conventional and -Omics Based Methods for Health Claims of Dietary Antioxidants: A Critical Overview," British Journal of Nutrition, Vol. 99, No. 1, 2008, pp. 3-52. doi:10.1017/S0007114508965752

[33] N. J. Kang, K. W. Lee, B. J. Shin, S. K. Jung, M. K. Hwang, A. M. Bode, Y. S. Heo, H. J. Lee and Z. Dong, "Caffeic Acid, A Phenolic Phytochemical in Coffee, Directly Inhibits Fyn Kinase Activity and UVB-Induced COX-2 Expression," Carcinogenesis, Vol. 30, No. 2, 2009, pp. 321330. doi:10.1093/carcin/bgn282

[34] T. W. Chung, S. K. Moon and Y. C. Chang, "Novel and Therapeutic Effect of Caffeic Acid and Caffeic Acid Phenyl Ester on Hepatocarcinoma Cells: Complete Regression of Hepatoma Growth and Metastasis by Dual Mechanism," FASEB Journal, Vol. 18, No. 14, 2004, pp. 1670-1681. doi:10.1096/fj.04-2126com

[35] J. J. Yan, J. Y. Cho and H. S. Kim, "Protection against Betaamyloid Peptide Toxicity in Vivo with Long-Term Administration of Ferulic Acid," British Journal of Pharmacology, Vol. 133, No. 1, 2001, pp. 89-96. doi:10.1038/sj.bjp.0704047
[36] J. R. Mein, F. Lian and X. D. Wang, "Biological Activity of Lycopene Metabolites: Implications for Cancer Prevention," Nutrition Reviews, Vol. 66, No. 12, 2008, pp. 667-683. doi:10.1111/j.1753-4887.2008.00120.x

[37] N. Druesne-Pecollo, P. Latino-Martel, T. Norat, E. Barrandon, S. Bertrais, P. Galan and S. Hercberg, "Beta-Carotene Supplementation and Cancer Risk: A Systematic Review and Metaanalysis of Randomized Controlled Trials," International Journal of Cancer, Vol. 127, No. 1, 2010, pp. 172-184. doi:10.1002/ijc. 25008

[38] C. S. Foote, "Definition of Type I and Type II Photosensitized Oxidation," Photochemistry \& Photobiology, Vol. 54, No. 5, 1991, p. 659. doi:10.1111/j.1751-1097.1991.tb02071.x

[39] M. B. Arnao, "Some Methodological Problems in the Determination of Antioxidant Activity Using Chromogen Radicals: A Practical Case," Trends in Food Science \& Technology, Vol. 11, No. 11, 2000, pp. 419-421.

[40] R. Amarowicz, "Lycopene as a Natural Antioxidant," European Journal of Lipid Science \& Technology, Vol. 113, 2011, pp. 675-677. doi:10.1002/ejlt.201100157

[41] R. Schmidt, "Deactivation of Singlet Oxygen by Carotenoids: Internal Conversion of Excited Encounter Complexes," The Journal of Physical Chemistry, Vol. 108, No. 26, 2004, pp. 5509-5513. doi:10.1021/jp048958u

[42] W. Stahl, A. Junghans, B. de Boer, E. S. Driomina, K. Briviba and H. Sies, "Carotenoid Mixtures Protect Multilamellar Liposomes Against Oxidative Damage: Synergistic Effects of Lycopene and Lutein," FEBS Letters, Vol. 427, No. 2, 1998, pp. 305-308. doi:10.1016/S0014-5793(98)00434-7

[43] N. M. A. Hassimotto, M. I. Genovese and F. M. Lajolo, "Antioxidant Activity of Dietary Fruits, Vegetables, and Commercial Frozen Fruit Pulps," Journal of Agricultural of Food Chemistry, Vol. 53, No. 8, 2005, pp. 2928-2935. doi:10.1021/jf047894h

[44] H. Palafox-Carlos, J. Gil-Chávez, R. R. Sotelo-Mundo, J. Namiesnik, S. Gorinstein and G. A. González-Aguilar, “Antioxidant Interactions Between Major Phenolic Compounds Found in 'Ataulfo' Mango Pulp: Chlorogenic, Gallic, Protocatechuic and Vanillic Acids," Molecules, Vol. 17, 2012, pp. 12657-12664. 